\title{
Coupling Geomechanics and Transport in Petroleum Engineering
}

\author{
M.B. Dusseault Earth and Environmental Sciences, University of Waterloo, Canada
}

\begin{abstract}
Transport-geomechanics coupling is of practical necessity in engineering when their mutual impact has a first-order impact (>10\%) on results. In soil mechanics, most design or analysis issues do not meet this criterion, hence coupling may not be of practical value. In petroleum geomechanics, however, coupling is usually necessary because the compressibilities of the mineral, the fabric and the fluid are similar.

Coupling involves a number of issues and levels. At one level, coupling of diffusion processes involves joint solution of heat flux, pressure propagation, ionic diffusion, and even electrical current effects. At the mechanics level, coupling these processes with geomechanics in a Biot poroelasticity formulation involves joint or iterative solution of the pressure, temperature and concentration fields along with the stress and strain field. At yet another level, there exist strong dependencies of transport properties on non-linear effects such as shear dilation, partial fabric collapse, joint aperture dilation, temperature and viscosity, and so on. Incorporating these non-linear effects into realistic mathematical modelling is the next major challenge in petroleum geomechanics.
\end{abstract}

\section{What is coupling?}

'Coupling' of processes in engineering analysis means combining the analyses of two or more physical processes in such a way that the effects of the processes on each other are rigorously included. Conversely, in an "uncoupled" analysis (or a 'one-way' analysis), such mutually interacting combined effects are ignored. In some circumstances, uncoupled analysis may suffice, providing one can demonstrate that the errors arising are not important in the context of the problem. For example, if the goal is a correct pressure and well flow prediction in a shallow aquifer of moderate matrix compressibility, a conventional flow solution, typically ignoring overburden reactions and using a constant compressibility, will likely suffice. However, if the matrix is extremely compressible, consolidation effects become of first-order importance and a coupled solution is needed. In this case, a full Biot stress-flow solution would be required (Biot, 1941). It has been demonstrated (Charlez, 1997; Rothenburg et al., 1994) that failure to correctly account for the coupled reaction of the surrounding strata to a pressure change in a well test can lead to prediction errors as large as $40-50 \%$, even in the case of purely elastic behaviour.

There are many different types of coupling, a few are listed here:

Stress-flow coupling means accounting for the consequences of effective stress (i.e. matrix and grain deformation) changes on flow behaviour, and accounting for the consequent changes in the pressure field on the effective stresses (Minkoff et al., 2003). This is the type of coupling most often considered in poromechanics, and there is a strong elastic mechanics framework for this (e.g. Zimmerman, 2000).

Static-dynamic stress-flow coupling (or inertial-diffusion coupling) means including the effects of inertial processes involving accelerations of the solid matrix and pore fluids on the diffusion behaviour of the pore liquids (Spanos et al., 2002). This new area has implications for improving fluid flow through exploiting the coupled dynamic behaviour of the solid matrix and the pore liquids.

Thermomechanical-flow coupling involves coupling thermal effects with stress-flow behaviour, including in the linear elastic domain factors such as viscosity changes, heat conduction, thermal convection (forced convection and density-driven convection), and in the non-linear domain factors such as permeability alteration from shear dilation, induced fracturing, even shale thermo-consolidation (Fung et al., 1994; Collins et al., 2002).

Chemo-mechanical-flow coupling occurs in fine-grained materials (clays, shales) with high surface area when changes in water chemistry leads to volume changes, permeability changes, effective stress changes, 
all simultaneously (Di Maio et al., 2002). It is of particular relevance in borehole stability in shales (Lomba et al., 2000) and in clay soil response to changes in salinity.

Electromechanical-flow coupling arises in fine-grained soils (and other media such as human tissue) as physical flow and volume changes are triggered by electrical potential fields, and in turn the changes in physical properties affect the potential field distribution (Huyghe et al., 2005).

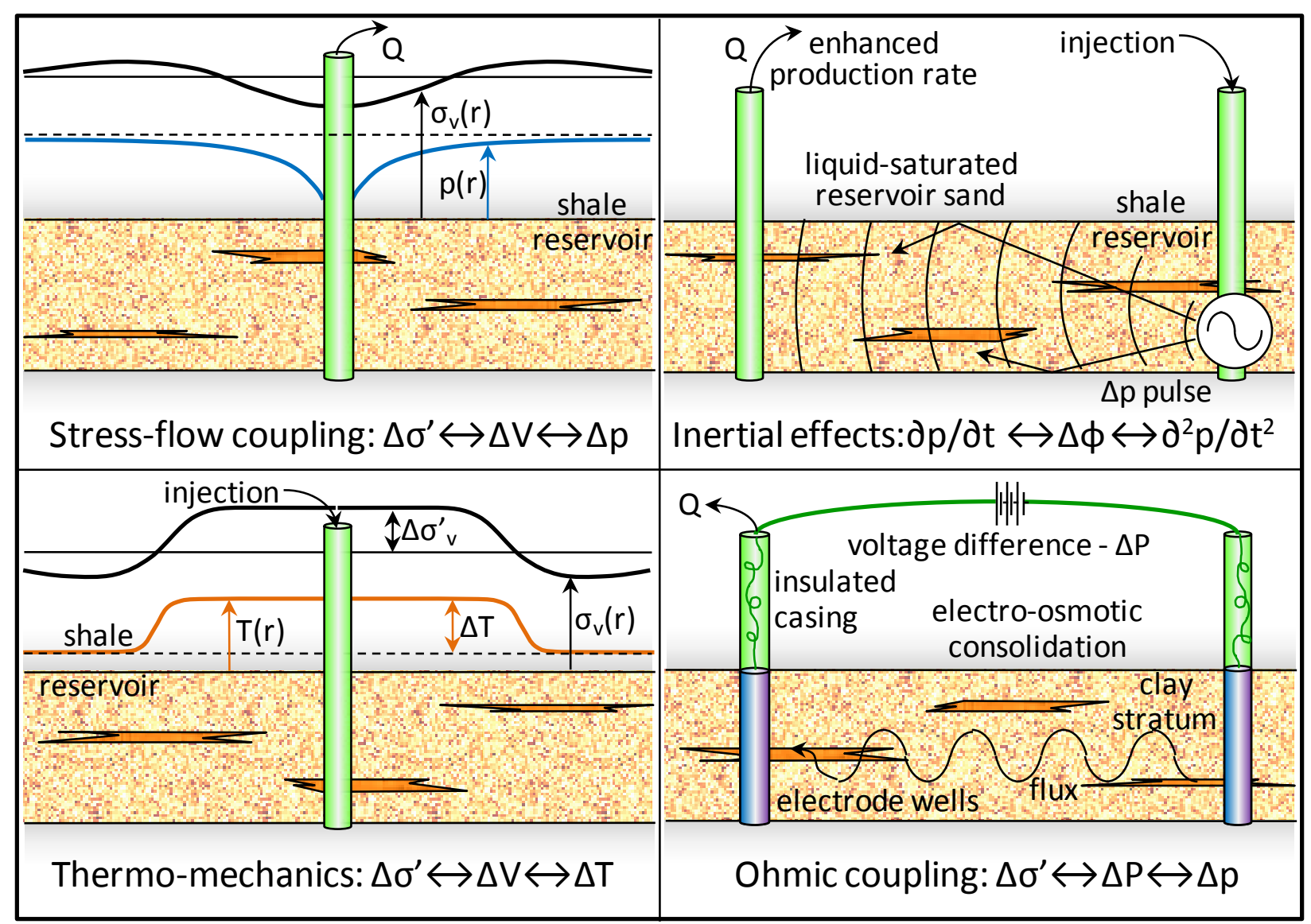

Figure 1 Several types of coupling to geomechanics problems involving $\Delta \sigma^{\prime}$ and $\Delta V$

\section{Approaches to stress-flow coupling}

\subsection{The soils mechanics approach to pressure changes}

In soil mechanics, the compressibility of the mineral matter and of the liquid in the pores is assumed to be far smaller than the compressibility of the soil skeleton, therefore it is assumed that a pore pressure change has the same effect on the three principal stresses such that $\sigma_{i j}^{\prime}=\sigma_{i j}-p$ and $\Delta \sigma_{k k}^{\prime}=\Delta p$. For a problem such as one-dimensional (1D) consolidation of a laterally extensive water-saturated clay layer subjected to a uniform vertical total stress change $\Delta \sigma$, (Terzaghi, 1943) assumed that because the water phase was so stiff compared to the skeleton, that $\Delta \mathrm{p}=\Delta \sigma$, and the excess pore pressure would slowly dissipate over time through 1D diffusion. This also led to the approximation in soil mechanics that the shear stress (deviatoric stress) is constant with a pore pressure change in a water-saturated material. Figure 2 shows, for example, the difference in a simple 2D stress state for the Terzaghi assumption versus a typical Biot calculation for the uniformly pressurised laterally extensive $(\mathrm{W}>>\mathrm{Z}$ ) uniform elastic reservoir.

Although Terzaghi (1943) was clearly aware of the simplifications he used, he was also aware that he needed to develop useful engineering tools for analysis, and in many cases his assumptions have proven robust. Biot (1941) and others extended his work, reducing the number of assumptions, and accounting for phase compressibilities more correctly through the "Biot parameter" $\alpha$, defined as $\alpha=1-\mathrm{K} / \mathrm{K}_{\mathrm{s}}$, where $\mathrm{K}, \mathrm{K}_{\mathrm{s}}$ are the matrix drained bulk modulus and the solid mineral bulk modulus respectively. $\mathrm{K}$ is always less than $\mathrm{K}_{\mathrm{s}}$, 
and in soils and high porosity unconsolidated sandstones, $\mathrm{K} \ll<\mathrm{Ks}$, so the approximation $\alpha \approx 1$ is reasonable for engineering purposes, it would seem. In Biot poromechanics, the Terzaghi effective stress law is usually expressed as $\sigma_{\mathrm{ij}}=\sigma_{\mathrm{ij}}^{\prime}+\alpha \mathrm{p}$. It is important to note that this is not the same as equations of the form $\Delta \sigma_{\mathrm{i}}=\Delta \sigma_{\mathrm{i}}^{\prime}+\Delta \mathrm{p}$, which are perfectly valid expressions used in computing stress changes.

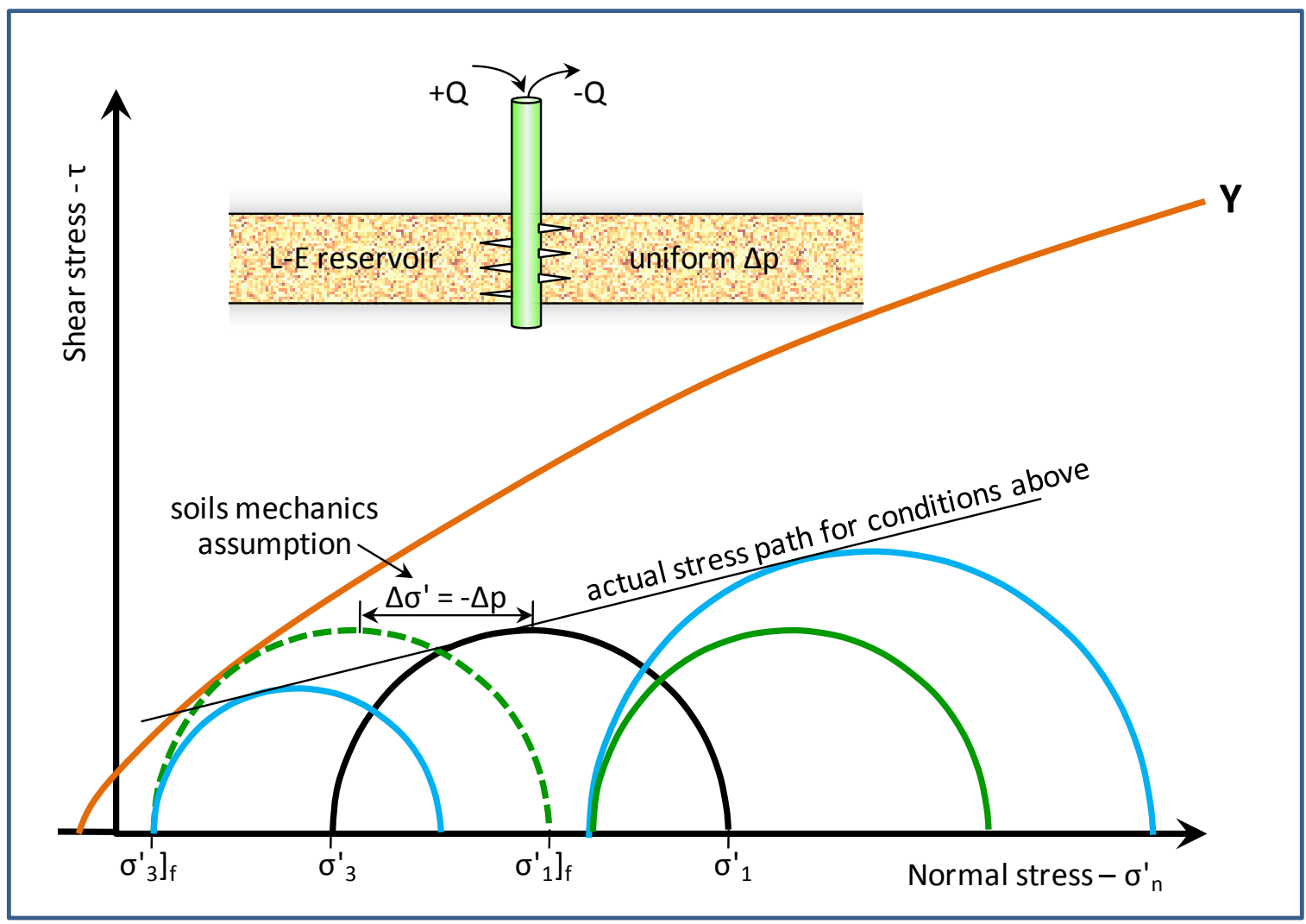

Figure 2 Contrasting the soils mechanics assumption for the effect of $\Delta \mathrm{p}$ with a partially coupled model

However, poromechanical coupling does not merely include incorporating all of the phase compressibilities and the boundary conditions correctly as in the Biot model. The reaction of surrounding rock, thermal effects, chemical effects, and other factors must be incorporated. For example, in thermal coupling, there is an expansion of the mineral grains as well as an expansion of the bulk rock during $+\Delta \mathrm{T}$, and all of the volume changes must be correctly computed, particularly for stiff reservoirs.

\subsection{Levels of coupling}

A geomechanics problem can be fully uncoupled, fully coupled, or partially coupled (Samier et al., 2006; Santamarina et al., 1998; Tortike and Farouq Ali, 1987). Perhaps the best way of assessing the level of coupling is to give examples.

Initially, reservoir engineering compaction analyses were performed in an uncoupled manner. The pressure field arising from well drawdown is solved in a convention flow simulation analysis where effective stresses are ignored. Then, a prediction of volume change is made from the pressure field $-\Delta \mathrm{V}_{1 \mathrm{D}}=\mathrm{C}_{1 \mathrm{D}} \Delta \mathrm{p}$ - without accounting for elastic behaviour or effective stress changes. Note that this equation is physically incorrect, as compressibility $\left(C_{1 D}\right)$ can only be used in terms of effective stress changes $-\Delta \sigma^{\prime}$. Conventional well equations (Horne, 1995) are fully uncoupled because they do not account for the true effective stress changes in the reservoir and the surrounding rock mass.

The first partially coupled solution was the consolidation problem, where the strain (degree of consolidation) is linked to pore pressure in a diffusion solution (Terzaghi, 1943). Later developments made the problem fully-coupled in the elastic domain ("poroelasticity") through correctly accounting for the compressibility of all of the phases (Biot, 1941; Showalter, 2002). Further extensions included two- and three-dimensional (2D 
and 3D) stress redistribution effects, greater degrees of coupling through linking porosity and permeability (Mesri and Rokhsar, 1974), thermal effects (Gatmiri and Delage, 1997), and so on, including chemical and osmotic effects, electro-kinetic effects, and Mitchell (1991) for the classic review of transport coupling.

Proper stress-strain and pressure-flux coupling involves correct accounting for all volume changes arising in the system, incorporating changes in material parameters that may arise, and analysing the problem with an appropriate mathematical formulation. In the limit, depending on the nature of the problem, full coupling may require incorporation of thermoelastic and heat flux effects, tensorial damage mechanics approaches, shear dilation and fabric evolution (tensorially evolving stiffnesses), and chemical processes.

\subsection{Analytical or semi-analytical approaches}

In any area of engineering analysis, the pursuit of closed-form solutions, either fully analytical or semianalytical (e.g. requiring the iterative evaluation of integrals), has direct value. Analytical solutions allow clear physical insight into coupled problems, quick estimates of effects, and validation of mathematical methods. Furthermore, many numerical methods are based in part on high-level integration of closed-form solutions. For example, if a Green's Function type of solution exists for a linear problem (Smith and Booker, 1993), it can usually be integrated to give a solution for a higher-order problem. An example in poroelasticity is the axisymmetric integration of the surface point load (the Boussinesq solution) subject to linear constraints to give the displacement-stress-flow solution (Paul, 1976).

Examples of solutions to coupled stress-flow problems have been widely published. For example, Rothenburg et al. (1994) presented the linear elastic stress-flow coupled solution to transient single-phase flow to a vertical well in a laterally infinite tabular reservoir stratum within a semi-infinite half space. To simulate the stress response of the near surface soil horizon to heat and mass flux, Malekzadeh and Pak (2008) have developed a coupled 1D analytical solution for a poroelastic unsaturated medium. The circular symmetry of a 2-D borehole attracts development of semi-analytical methods (Detournay and Cheng 1988).

The disadvantages of closed-form or semi-analytical coupled solutions are well-known:

- Only a limited degree of coupling can be accounted for (e.g. one form of coupling only - Wang and Dusseault, 2003).

- Constitutive laws must in general be linear (e.g. elasticity, constant $\mathrm{k}$ and $\mathrm{C}_{\mathrm{c}}-$ Rothenburg et al., 1994).

- Loading must be simple (e.g. single vertical well, constant load on the boundary, uniform pressure drop...).

- Boundary conditions must be constant (e.g. constant far-field stresses, constant flux or constant pressure at the wellbore face).

- The geometry must be simple (e.g. plane-strain, point source, axi-symmetric, etc.).

\subsection{Mathematical modelling approaches in petroleum reservoir simulation}

Pseudo-coupling, or limited partial coupling, can be implemented in many ways. One example is a reservoir simulator that computes a porosity change, based on pressure changes and compressibility functions, but not based on coupled effective stress changes (e.g. Ghaboussi and Wilson, 1973). The pressure change from the simulator is converted to a porosity change which is then empirically linked to permeability changes through some function such as a Carman-Kozeny or other empirical equation (Tran and Nghiem, 2005). The changed permeability may then be used in the next simulation step.

The term "one-way coupling" is sometimes used to refer to volume change calculations based on a pressure field (Tran and Nghiem, 2005). For example, the pressure field from a conventional simulator is introduced into a geomechanics simulator to compute stresses based on the strains arising from the effective stress changes, but there is no back-linkage of the pressure solution to the changes in effective stresses, nor is there any accommodation of the response of the surrounding strata.

Iterative (two-way) coupling involves both a geomechanics simulator and a flow simulator. At a time step, pressures are solved, sent to a geomechanics simulator where strains are solved; then, these strains are sent 
back to the flow simulator as source/sink nodal loads. Pressures are corrected with these inputs, and iteration repeated to the desired precision level. This method allows highly sophisticated flow simulators to be used with highly sophisticated geomechanics simulators (Gai et al., 2003; Dean et al., 2006). Iterations are robust and rapidly converging; also, to reduce computational effort, the geomechanics simulator can be invoked only every 10-20 time steps.

Full coupling means that fluid flow and displacement calculations are executed simultaneously (Chin et al. 2000; Settari and Mourits, 1998; Stone et al., 2000; Thomas et al., 2002.). This will be generally slower than iterative coupling and for complex non-linearities such as shear dilation, non-linear elasticity, tensorial properties (e.g. induced fabric - Rothenburg and Bathurst, 1989), and sharp thermal fronts (Yin et al., 2008a), stability problems may be more common than with iterative coupling. However, full coupling is the "gold standard" of mathematical approaches to coupling.

\section{Is coupling too difficult?}

Full coupling of all processes and non-linearities in a general framework is too difficult to implement, and may so remain for some time. Later, several examples of thermal oil extraction processes will be given; these are economically important processes that have not yet been fully analysed in a coupled manner at a realistic engineering scale. Such lacuna may be for several reasons; several of them are described here.

The problem may be computationally intractable. In structurally complex environments, reservoir analysis involving injection and production in many wells (e.g. 20-50) can easily lead to $10^{7}-10^{8}$ degrees of freedom (equations), especially if there are many steep gradients in p, T, $\sigma^{\prime}$ and saturations (Yin et al., 2008a). Also, non-linear behaviour such as shear dilation, fabric collapse, fracture orientation changes, all combined with changes in $\mathrm{k}, \mathrm{C}_{\mathrm{c}}$, and $\phi$, make computational efforts exceptionally large. Of interest to reducing computational effort is a method combining finite elements for the reservoir with displacement discontinuity elements for the surroundings (Yin et al. 2008a, see Figure 3). This method treats the exterior zone as elastic (not necessarily isotropic), the interior zone of reservoir rock which may undergo non-linear behaviour of various kinds (e.g. dilatancy, collapse, etc.), and an intermediate zone in which temperature and pressure changes (and hence, stress changes coupled to $\Delta \mathrm{T}$ and $\Delta \mathrm{p}$ ) are important. Compared to classical finite element approaches, the number of degrees of freedom can be reduced by a factor of five or so.

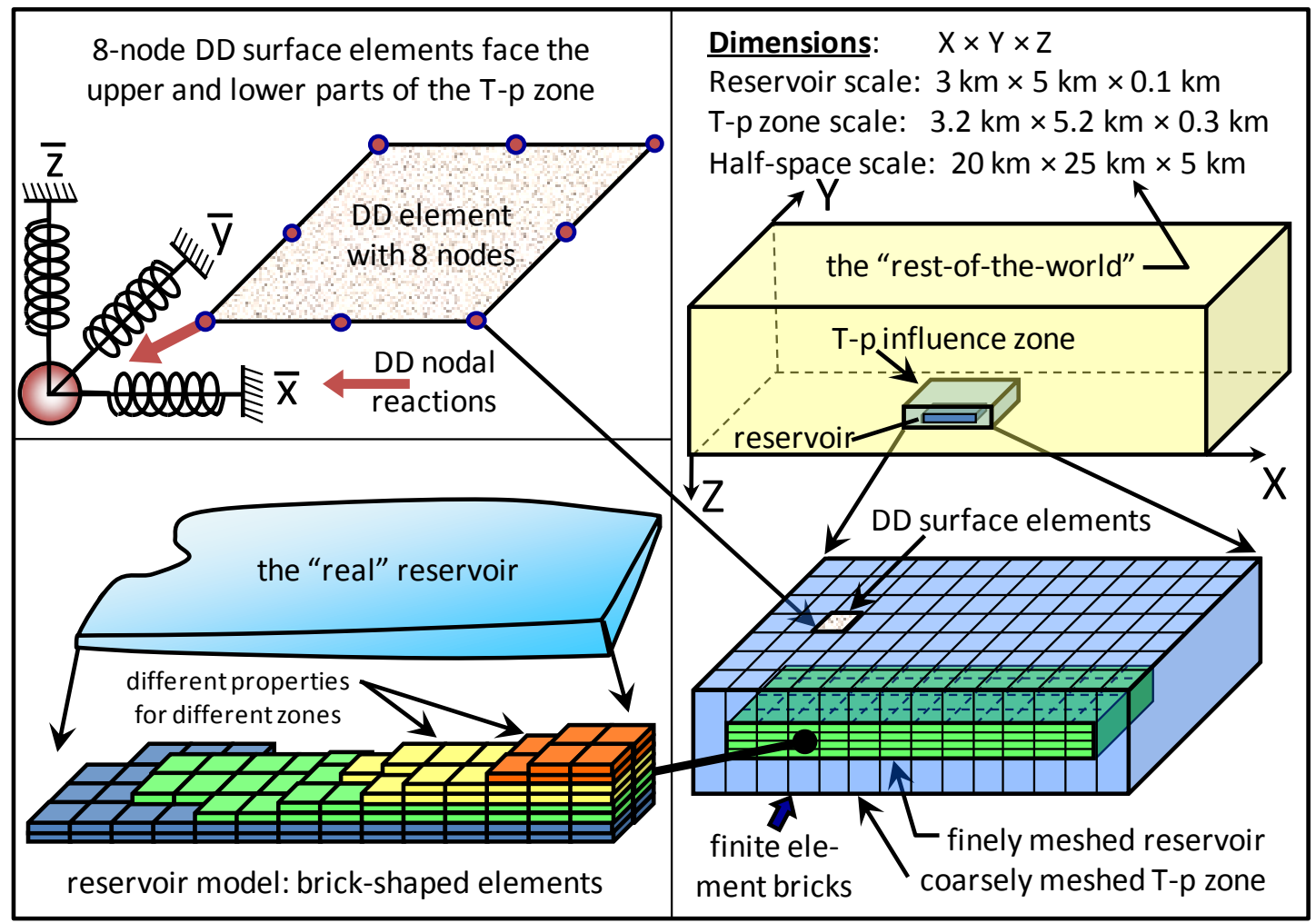

Figure 3 A DD-FEM scheme for reservoir engineering analysis of tabular reservoirs 
Vital data may be lacking. For example, in a shale oil extraction technology that involves electrical heating and induced pyrolysis, all four basic diffusion processes are important and coupled (Darcy flux, Fourier flux, Fickian flux, Ohmic flux; see Mitchell, 1991). Complex pyrolysis reactions are generating liquid and gaseous phases through thermal decomposition of solid kerogen, hence pressure-volume temperature behaviour is important. These changes trigger massive $\sigma^{\prime}$ alterations, and fracturing takes place, in large part because shale is dehydrated $\left(\sim 125^{\circ} \mathrm{C}\right)$, then dehydroxylated $\left(\sim 400^{\circ} \mathrm{C}\right)$, with massive volume shrinkage taking place. Permeability changes of five to seven orders of magnitude develop, and reaction stochiometry over large $\mathrm{p}-\mathrm{T}$ ranges in the presence of clay minerals are ill-understood. Hence, any attempt at generating a sensible coupled model is severely constrained by the lack of constitutive behaviour for the rock and fluids undergoing pyrolysis. In such cases, better-defined subsets of process will be analysed in a coupled manner, rather than trying to develop a "complete" model.

Geomechanics behavioural criteria may be inadequate. Consider massive slurried solids injection into permeable sandstones, a process now being used industrially at a number of sites (Nadeem and Dusseault, 2007). Rigorous coupled analyses, even in the isothermal and non-reactive case, appear to involve many issues that are improperly simulated, or accounted for empirically only. Injection takes place under fracturing conditions, but the solids filter out on the fracture walls, changing the liquid leak-off rate, and forcing the fracture to become wider so as to sustain injection. During this process, solids filtration, consolidation, and $\mathrm{p}$ and $\sigma^{\prime}$ changes take place simultaneously. Aperture growth increases $\sigma_{3}$ until fracture orientation changes occur, and the process continues with repeated new fracturing to generate a complex fracturing zone. Currently, the geomechanics community does not understand when and how fracture orientations take place during solids injection, despite vast amounts of monitoring data collected during the solids injection process. Without this knowledge, attempting to execute fully coupled models may be inappropriate.

Complexity may be intense. Heterogeneity, process complexity, geometrical and constitutive uncertainty may, in aggregate, be so large that executing a coupled model in an attempt to make a prediction is unwarranted. In this situation, the proponent must decide on one of two directions: abandon the attempt at coupling and perhaps even modelling, or, treat the coupled modelling attempts not as a predictive model, but as a parametric or physics model used to gain insight into the potential magnitude of the effects or their consequences. In fact, given typical complexity of many thermal petroleum recovery processes, much coupled geomechanics modelling serves exactly this role. In the casing shear problem described later, a close correspondence between reality and predictions is rarely obtained without a substantial attempt at calibration of models to field measurements.

Coupling may not be warranted. For engineering processes, there are three levels of importance. A phenomenon of "first-order" importance will have $>10 \%$ effect on the results; it must be included in design and analysis. Simple coupled models are used to assess whether this magnitude is to be expected. Phenomena of "second-order" importance, 1-15\% effect, may or may not be included in coupled analysis, depending on the general level of uncertainty. For example, in foundation analysis, factors of safety are usually so high that second-order coupling effects are not analysed, although they may be noted and flagged for observation. "Third-order" processes, giving less than 1-2\% on results, are not included in coupled geomechanics analysis. For example, large temperature differences associated with steam injection in oil sands give rise to induced electrical currents, but these are of no consequence to the rest of the process.

\section{Coupling in several classical problems}

\subsection{The reservoir compaction - surface subsidence problem}

A simple example of an uncoupled analysis is the 1D reservoir compaction problem for a laterally extensive, tabular reservoir. A flow problem is solved to give a change of pressure $-\Delta \mathrm{p}-$ which is then used to calculate the change in effective stress $-\Delta \sigma^{\prime}{ }_{v}$ - which is then used to calculate the deformation. This process actually does not involve a true calculation of stress change because it is assumed that the pore pressure change is equal to the effective stress change: $\Delta \mathrm{p}=-\Delta \sigma_{\mathrm{v}}^{\prime}$. Then, the vertical deformation of the reservoir is calculated as $\Delta \mathrm{z}=-\Delta \sigma_{\mathrm{v}}^{\prime} \cdot \mathrm{H} \cdot \mathrm{C}_{\mathrm{c}}$, where $\Delta \mathrm{z}$ is the change in thickness of the reservoir in the vertical direction, $\mathrm{H}$ is the thickness of the reservoir, and $\mathrm{C}_{\mathrm{c}}$ is the coefficient of compressibility. This process, sketched in Figure 2 for an infinitely wide reservoir subjected to a uniform $\Delta p$, need not invoke the reaction of the surrounding rocks; of course, although of interest, this is a severely restricted limiting case. 
For a more complex case of a limited area reservoir, Geertsma (1973) solved a partially-coupled subsidence problem using mathematical integration of the "nucleus of thermoelastic strain" for a disk-shaped reservoir. Still, this solution is incompletely coupled because of the previous assumption (that $\Delta \mathrm{p}=-\Delta \sigma_{\mathrm{v}}^{\prime}$ ). Leaving aside the linear elastic compressibility assumption (in reality, $\mathrm{E}=f\left(\sigma^{\prime}\right)$ ), what are the practical deficiencies of this approach? The assumption that $\Delta \mathrm{p}=-\Delta \sigma^{\prime}$ is the same as saying that the vertical total stress is constant, hence $\Delta \sigma_{v}=0$. On the right hand side of Figure 4, for a reservoir that has the shape of an elliptical inclusion, the actual effect on the stress field of a drop in pore pressure is sketched. The behaviour is as follows:

- Liquid withdrawal $(-\Delta \mathrm{p})$ leads to an increase in effective stress $\left(+\sigma^{\prime}\right)$ in the volume.

- A small volume shrinkage $(-\Delta \mathrm{V})$ occurs because of the stress increase $\left(+\sigma^{\prime}\right)$.

- Surrounding rocks are elastic, therefore the $-\Delta V$ in the ellipse leads to a stress re-distribution, often called stress arching.

- Note that stress redistribution must occur to maintain stress equilibrium.

- Thus, the total stress is not constant because of this arching (as long as the inclusion is substantially narrower than the zone height - Figure 4 ), which means that $+\sigma^{\prime}$ is less than expected, thus the compaction is less than expected.

- To generate significant subsidence at the surface, the width of the compacting zone in the reservoir must be $>Z$, the depth; otherwise, the compaction strains are accommodated by overburden arching.

- Hence, arching leads to a delay in full subsidence development, dependent on scale effects.

- When the width of the compacting zone is greater than $\sim 1.5 \mathrm{Z}$, the overburden beam is insufficient to sustain the arch, and there is a reloading of the reservoir, triggering greater subsidence, but delayed in time.

Examining vertical and horizontal planes near the "inclusion" in Figure 4, the redistribution of the stresses is evident; hence, total stresses acting on the planes are not constant but reflect the $\Delta p$-induced strain effects.

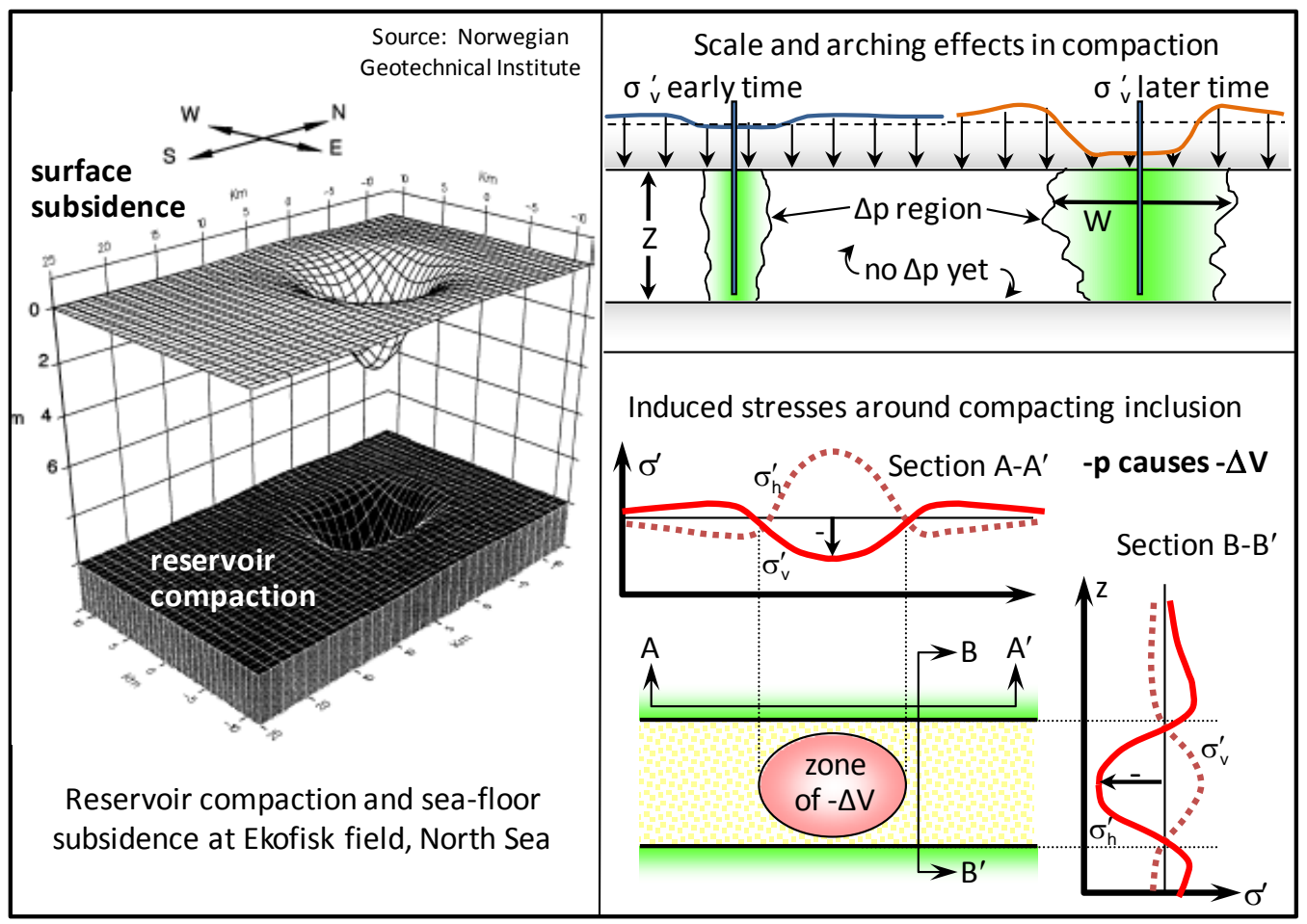

Figure 4 Some effects of reservoir compaction: surface subsidence, scale effect, arching, stress changes 
Another fundamental issue in real subsidence cases is that the behaviour of a strongly compacting stratum is invariably non-linear. In the case of the North Sea Ekofisk oilfield subsidence (>8 m between 1971 and 2008 ), massive collapse of a quasi-stable fabric from $\phi \approx 40-50 \%$ to $\phi \approx 30-40 \%$ took place as production generated pressure drawdown, increasing $\sigma^{\prime}$ until the fabric collapsed (a "house-of-cards" phenomenon). In the case of the California Wilmington oilfield subsidence ( 9 $\mathrm{m}$ between 1922 and 1961) before repressurisation), no collapse was observed, but a $\Delta$ p-induced porosity drop from 34 to $\sim 30 \%$ over many thick stacked reservoir intervals continued until companies were forced to actively provide pressure maintenance. Interestingly, repressuring led to $\Delta \mathrm{z}$ recovery of only a few percent, $>90 \%$ of the subsidence was permanent. Hence, a correctly coupled time-dependent subsidence analysis approach must take into account the full reaction of the surrounding strata as well as the elastoplastic behaviour of the compacting rock.

Yet another phenomenon endemic to large-scale subsidence is formation shear (Dusseault et al., 2001; 2007). Bending stresses associated with differential subsidence lead to strong concentrations of shear stress along lithological interfaces which have stiffness contrasts (typically sandstone-shale interfaces). Slip occurs when the shearing criterion is exceeded, and this leads to load redistributions, hence more isothermal coupling effects. Incorporating these plasticity and "whole-world" effects into a fully coupled 3D numerical analysis of a field response remains a challenge, in part because of the size of the problems (Chin and Nagel, 2004; Osorio et al., 1999; Settari, 2002; Yin et al., 2008a).

The subsidence phenomenon is also coupled in a sense with earthquake dynamic processes because differential subsidence (or heating, high pressure injection, or depletion, etc.) can lead to microseismic activity or earthquakes (Ottemöller et al., 2005). In this case, once stresses generated by coupled processes exceed the limit, a dynamic stress relaxation stick-slip event occurs, and stresses are redistributed. Of course, much geophysics work has been done in the area of classical Biot coupling between quasi-static diffusion processes and stress (Cocco and Rice, 2002), but not in the full seismomechanically coupled regime.

\subsection{Coupled flow to a well}

The original Theis solution for flow to a single vertical fully penetrating well in a planar laterally infinite reservoir (Muskat, 1937), and all subsequent semi-analytical solutions to variants of this problem, including transient flow cases, horizontal and inclined well cases, all ignore coupling of flow with stress changes. In fact, the boundary condition implicitly assumed in all these well equations is that $\sigma$ is constant, hence $\Delta \mathrm{p}=-\Delta \sigma^{\prime}$, which cannot be true, as outlined above.

For the axi-symmetric case described, for singe-phase flow, a full Biot poroelastic solution was developed by Rothenburg et al. (1994); (Charlez, 1997) for the infinite radius reservoir as well as for the reservoir of finite radius with respect to the formation thickness. Briefly, it turns out that the coupling effects are far more important for liquid flow, compared to gas flow, because of the compressibility differences. The formation thickness and the contrast between the reservoir compressibility and the overburden compressibility are the major factors that control the effect on flow to the well. For example, if the overburden is extremely compressible compared to the reservoir (never the case in the real world), the assumptions of Theis (Muskat, 1937) are recovered.

If the overburden is extremely incompressible, massive arching occurs with large changes in all effective stresses. For intermediate compressibility ratios interesting stress transfer effects similar to the MandelCryer consolidation effect (Cryer, 1963) take place, but in well mechanics these effects arising during drawdown are called the Noordbergum effect, apparently first mentioned by Verruijt (1969).

In the most challenging conditions for well testing (large thickness, short time), massive arching near the wellbore can lead to errors approaching 50\% if the data are interpreted with conventional well test equations. This is not a trivial value; the economic implications are large. It should be of some concern that great reliance is paced on well test data to make economic decisions, yet no commercial well test packages include the potentially first-order effects of stress-flow coupling. 


\subsection{Diffusive - dynamic coupling in porous media}

No coupled mathematical model will identify new relevant physics; however, from its inadequacies and poor predictions we may deduce that a model is incomplete, triggering the search for other important coupled physical and chemical effects. Nevertheless, what seems at one time to be logical and self-evident may later turn out to be incorrect, or at the least, incomplete, so it is necessary to limit assumptions to those that can clearly be demonstrated to be valid.

An example related to coupling is found in the seminal work of Biot $(1956 \mathrm{a} ; 1956 \mathrm{~b})$ but in the area of diffusive-dynamic coupling rather than static mechanical-flow coupling. Biot assumed that a representative elementary volume (REV) could be defined in multiphase porous media, and that a single energy function for dynamic (inertial) processes could be developed for this REV. It turns out that this assumption is inadequate in low-frequency seismic excitation $(<10 \mathrm{~Hz})$. A more rigorous physics-based derivation shows that for a medium with $\mathrm{N}$ interpenetrating contiguous phases, $\mathrm{N}$ energy functions must be written (de la Cruz et al., 1993). These energy functions are coupled and subject to thermodynamic and other physical restrictions (de la Cruz and Spanos, 1985; 1989), but they cannot be lumped together into a single monotonic energy function. Failure to recognise this has held back the development of seismo-dynamic analysis in areas such as earthquake triggering (Geilikman et al., 1993), increased fluid flux related to low frequency excitation (Spanos et al., 2002; Manga et al., 2003; Montgomery and Manga, 2003). A major practical aspect of static-dynamic coupling is the recent development of large-amplitude excitation methods to assist flow in porous media (Spanos et al., 2003); a technology now used in oil well workovers and in flow enhancement.

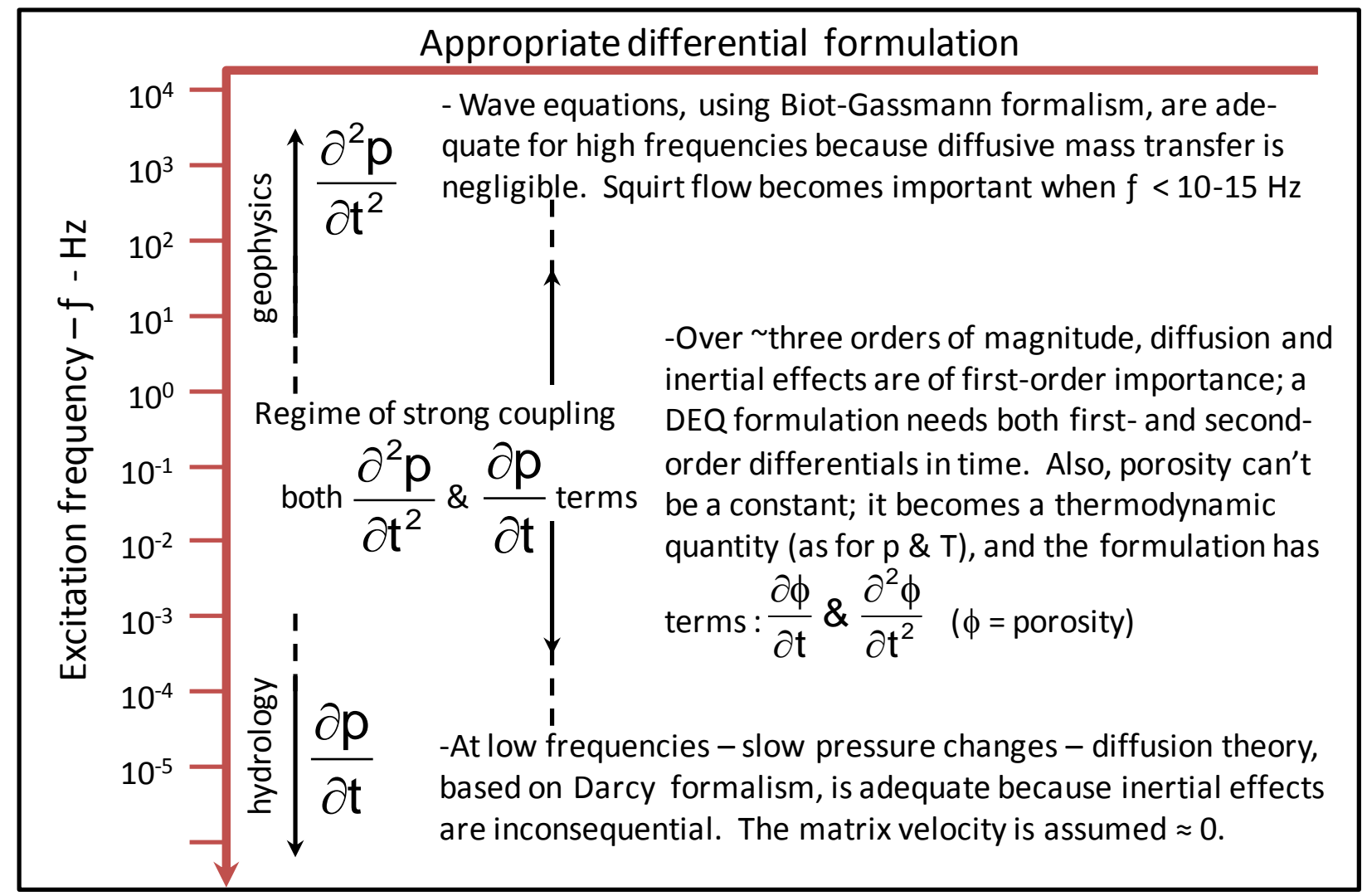

Figure 5 From Darcy to Biot: a continuum of excitation frequencies, thus diffusive-inertial coupling

Another example that arises in Biot seismo-dynamic analyses (Biot-Gassmann formalism) is that porosity is conventionally treated as a constant, implying that the following conservation equation is zero: $\partial \phi / \partial / \mathrm{t}=\rho_{\mathrm{s}} \nabla \mathrm{v}_{\mathrm{s}}-\rho_{\ell} \nabla \mathrm{v}_{\ell}$, where $\rho$ and $v$ are phase density and velocity for solid (s) and liquid $(\ell)$ phases. Interestingly, this basis for consolidation theory (low frequencies) was assumed to be irrelevant for seismic frequencies. However, at low frequencies when the liquid and the solid can move out-of-phase, it is clearly an incorrect assumption; the whole empirical treatment of the squirt flow phenomenon at low frequencies 
(Berryman, 1988; Mavko et al., 1998; Nur, 1971), as well as the non-thermodynamic treatment of attenuation behaviour, can be taken as direct proof of the incompleteness of the Biot-Gassmann formalism over the entire range of frequencies. Perhaps the strongest physical argument that dynamic-diffusive coupling through inertial porosity changes takes place is shown in Figure 5. At low frequencies, Darcy flow theory suffices to describe important effects; at high frequencies, Biot-Gassmann formalism suffices. However, because the frequency domain is a continuum, there must be approximately two orders of magnitude over which both inertial and diffusion effects are of first order. Depending on phase compressibilities, these two orders of magnitude lie in the range of $10^{-3}-10^{0} \mathrm{~Hz}$, just below conventional seismology frequencies, and above conventional diffusive flow frequencies. It appears that at the transition frequency where the liquid phase begins to behave incompressibly $\left(10^{-1}-5 \times 10^{-1} \mathrm{~Hz}\right)$, it is possible to generate slow soliton waves in liquid-saturated permeable media. Some interesting possibilities arise, such as a better explanation for remote earthquake triggering, and an explanation for aquifer response to remote earthquake excitation.

Note that coupling at low frequency oscillatory excitation of pressure was developed as a means of measuring both permeability and compressibility of a low permeability specimen using the combination of phase shift and attenuation (Kranz et al., 1990), but this solution is not a true dynamic (inertial) solution.

\section{Some coupling issues in heavy oil thermal extraction}

There are likely eight to nine $\mathrm{Tb}$ (trillion barrels, $1 \mathrm{~Tb} \sim 160 \times 10^{9} \mathrm{~m}^{3}$ ) of heavy oil and bitumen trapped in porous rocks worldwide, twice the amount of low-viscosity conventional crude oil. Thermal methods (steam injection, in situ combustion, electrical heating, etc.) are the most likely candidates for extraction, and this gives rise to interesting and economically extremely important coupling issues. In this section, some of the coupling effects are explained. In any thermal process in viscous oil, the heat reduces the viscosity of the oil, which then can flow to a well, and the oil is almost always replaced in part by a low-viscosity phase such as a gas or hot water, changing the phase saturations, hence the relative permeabilities. Although these FourierDarcy couplings are fundamentally important to reservoir engineering, the following discussion focuses mainly on geomechanics-related coupling phenomena.

\subsection{Steam-assisted gravity drainage (SAGD) in a sandstone}

Figure 6 shows a perpendicular slice of a group of SAGD chambers, as well as an axial slice of one SAGD well pair; typically, $\mathrm{H}=20-35 \mathrm{~m}, \mathrm{~W} / \mathrm{H} \approx 3.5-4$ and $\mathrm{L}=750-1000 \mathrm{~m}$.

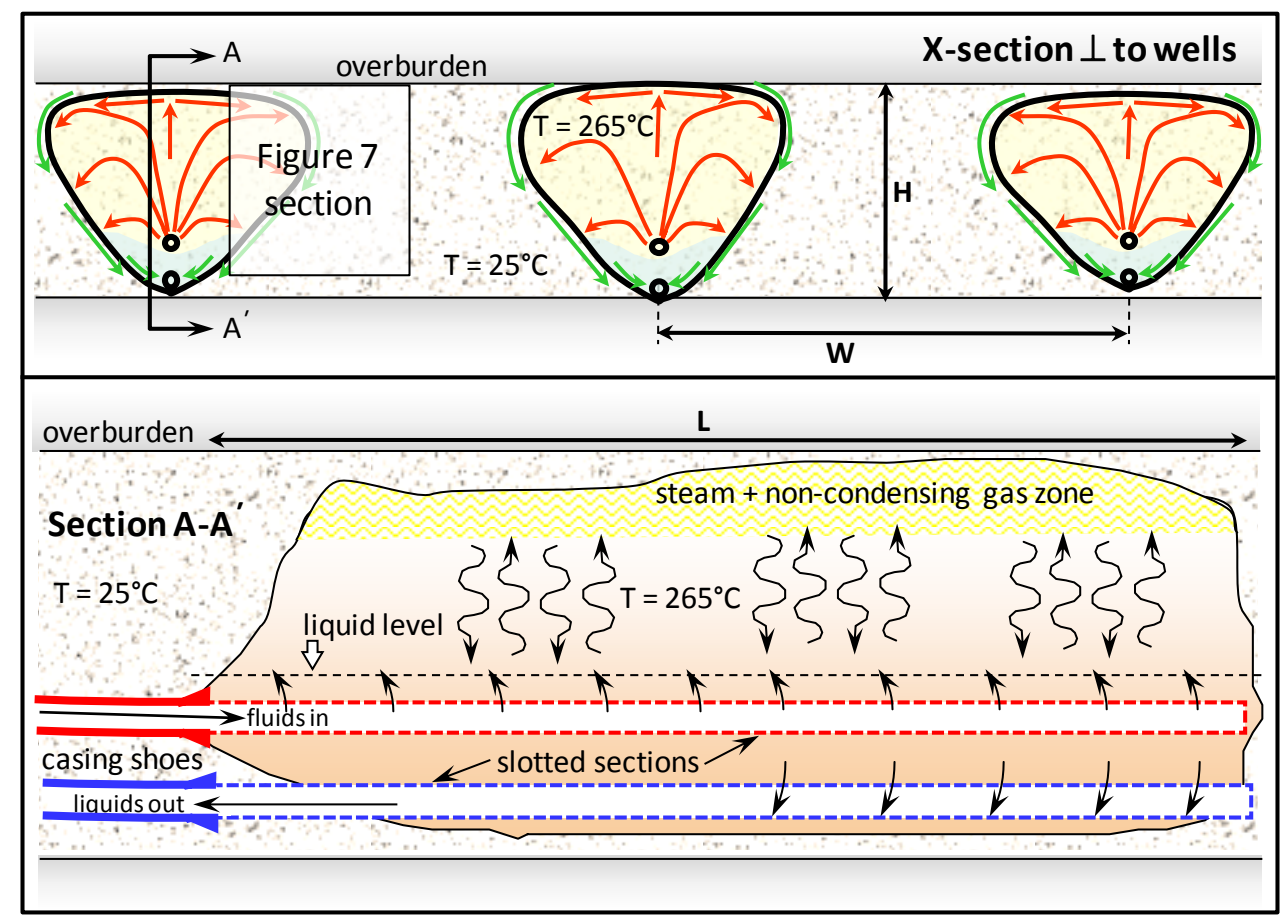

Figure 6 The geometry of the SAGD process 
The upper X-section is a plane-strain section. Gravity drainage takes place out at about the virgin $\mathrm{p}_{\mathrm{o}}$, so there is no significant regional flux arising from induced pressure gradients. Steam rises under gravitational thermal segregation, moves laterally, condenses into water, and flows along with hot oil toward the producing well. Although there are no induced pressure gradients, the phase density difference $-\Delta \rho-$ dominates flow because of the difference in head $(\Delta \rho \cdot g \cdot z)$, and the flow rate is of course proportional to the vertical permeability, an intrinsic material property.

Assuming $\mathrm{H}=30 \mathrm{~m}, \mathrm{Z}=500 \mathrm{~m}$ with initial conditions $\mathrm{T} \sim 25^{\circ} \mathrm{C}, \sigma_{\mathrm{v}}=\sigma_{\mathrm{h}} \sim 12 \mathrm{MPa}$ and $\mathrm{p}_{\mathrm{o}} \sim 5 \mathrm{MPa}$, the equilibrium $\mathrm{T}$ of the steam at $5 \mathrm{MPa}$ is $265^{\circ} \mathrm{C}$, thus $\Delta \mathrm{T} \sim 240^{\circ} \mathrm{C}$. A typical thermal expansion coefficient of $\phi$ $=0.28-0.30$ quartz sand is $8-10 \times 10^{-6} /{ }^{\circ} \mathrm{C}$, and the elastic parameters are on the order of $\mathrm{E} \sim 3 \mathrm{GPa}, v=0.25$.

When a group of SAGD steam chambers under these conditions is 'grown', the surface of the ground rises by about $400-500 \mathrm{~mm}$. However, a thermoelastic calculation, even assuming $100 \%$ of the volume of the reservoir is heated to $265^{\circ} \mathrm{C}$, gives $(0.000010 \cdot 240 \cdot 30) \sim 70 \mathrm{~mm}$, about $15 \%$ of the $\Delta \mathrm{z}_{\max }$ measured. Because pore pressures are approximately constant, there is no confining-stress-related dilation, which would be small in any case (the compressibility effect). Therefore, the rest of the vertical heave must be the result of fabric dilation, which can only happen if high shear stresses are generated, under either hot or cold conditions.

Consider the limiting case where the entire stratum is homogeneously heated to $265^{\circ} \mathrm{C}$ assuming that nolateral-strain in horizontal directions is possible, $\varepsilon_{\mathrm{x}}=\varepsilon_{\mathrm{y}}=0$, the purely thermoelastic stress changes become:

$$
\Delta p=0, \Delta \sigma_{v}=0, \therefore \Delta \sigma_{v}^{\prime}=0, \quad \text { so } \Delta \sigma_{x}^{\prime}=\frac{E \cdot \beta \cdot \Delta T}{1-v}
$$

For the parameters listed previously, this approximation gives $\Delta \sigma^{\prime}{ }_{\mathrm{x}} \sim 10 \mathrm{MPa}$, or $\sigma_{\mathrm{v}}^{\prime} \sim 7 \mathrm{MPa}, \sigma_{\mathrm{h}}^{\prime} \sim 17 \mathrm{MPa}$. However, this is insufficient for shearing and dilation to develop.

Another analysis that accounts for the non-uniform distribution of strain leads to a different conclusion. The section shown in Figure 7 is a plane-strain slice of the SAGD process after some time.

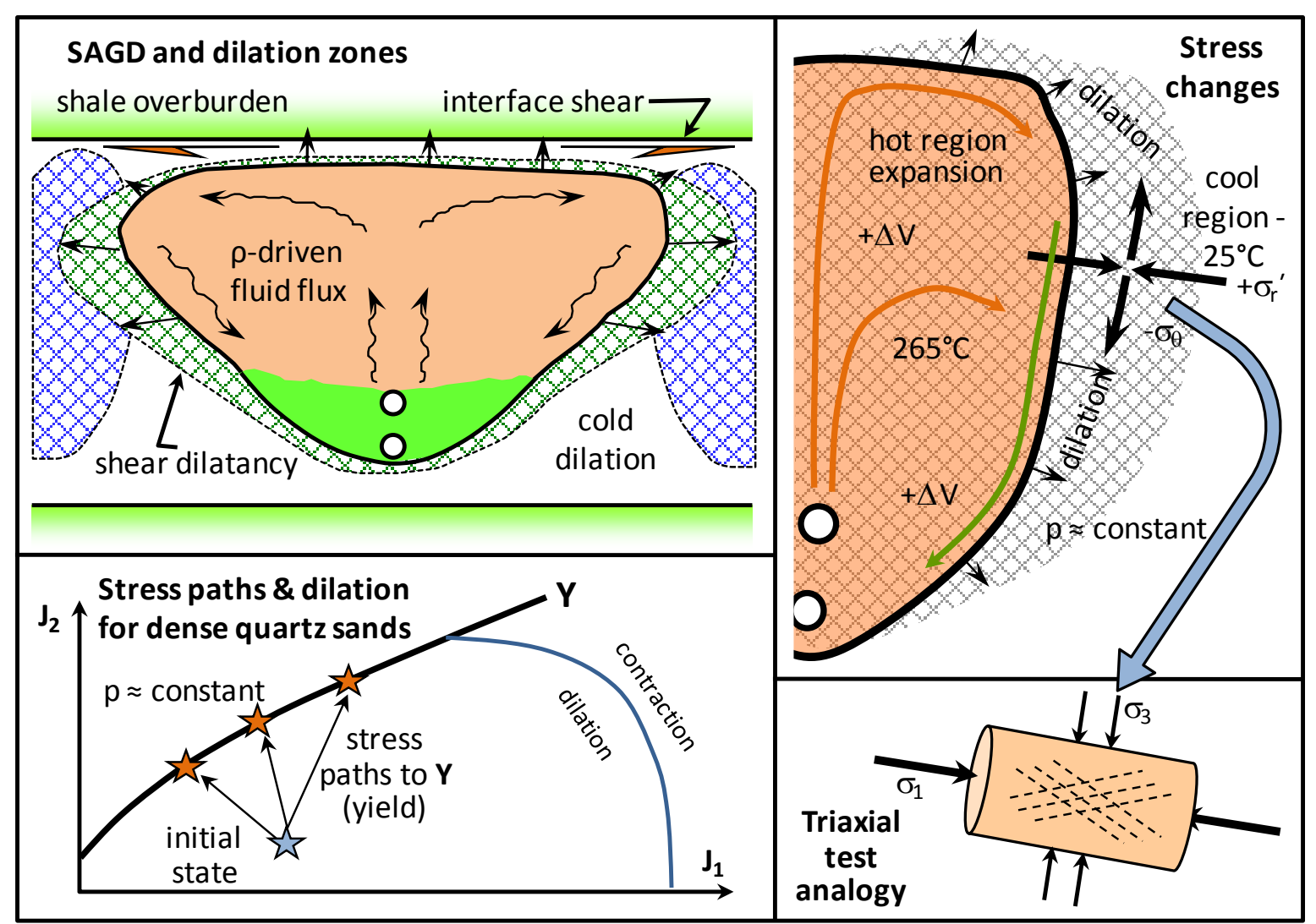

Figure 7 SAGD: dilation in advance and around the expanding heated chamber 
The key observation is that in advance of the thermal front, stress changes applied to the reservoir sand are compressive in the horizontal direction (approximately), but because the SAGD chamber is also expanding vertically, the vertical stress is diminished substantially, taking the deviatoric stress sharply into a condition of shear failure at low confining stresses. In fact, even at $\Delta \mathrm{T}$ as low as $100^{\circ} \mathrm{C}$, the vertical stress drops below the pore pressure value for any reasonable set of mechanical parameters. This leads to dilation and changes of properties. The set of phenomena that probably take place are:

- Injection of steam leads to thermal expansion of the steam chamber in all directions.

- In advance of the chamber wall, the reservoir sand is subjected to strong compression in the horizontal direction and extension in the vertical direction.

- Depending on properties assumed and the shape of the heated zone, changes in deviatoric stress $\left(\sigma_{1}-\sigma_{3}\right)$ can easily exceed $20 \mathrm{MPa}$.

- Shearing takes place once the local shear yield criterion is satisfied.

- Because of the moderate $\sigma_{3}^{\prime}$, a large amount of dilation accompanies the shearing process.

- Because of the geometry of the thermal zone and the reservoir, shear occurs throughout the reservoir, not along just a few planes; hence, general dilation ensues in advance of the thermal front.

- As the steam chamber grows, previously dilated material is progressively incorporated into it. Within the steam chamber, the compressive stresses are higher, some dilation is lost by compression - or "re-compaction", but this is small in relation to the dilation.

- The strong dilation in front of the heated zone leads to:

- An increase in absolute permeability by perhaps $\mathrm{x} 2$ to $\mathrm{x} 5$ because of porosity increase.

- Breaking up thin clay dustings on bedding planes and shale layers a few $\mathrm{cm}$ thick, further increasing permeability (especially $\mathrm{k}_{\mathrm{v}}$, which controls gravity drainage rate).

- The strong porosity increase (probably 4-6\% locally) causes water influx (the oil is far less mobile), so the water permeability increases by at least an order of magnitude (likely much more), allowing thermal convection to develop in advance of the zone where the oil is being "melted" by the high T.

- These permeability increases and accelerated heat transfer mechanisms make gravity drainage much more efficient, allowing heat flux to become dominated by convection in the dilated zone in front of the steam chamber.

Again, note that fluid flow heat flux (Fourier), and geomechanical response are intimately coupled. The mechanism of dilation-induced improvements in properties is a major reason why SAGD has proven far more successful in practice than initial simulation results suggested (Collins et al., 2002; Collins, 2007). It is also one of the reasons why petroleum engineers have to calibrate and re-calibrate non-coupled models, generating solutions formulated in terms of "pseudo-parameters" or empirically changing properties because it is impossible to make realistic predictions using virgin properties. Because large permeability enhancement related to stress-induced shearing accompanies the process, SAGD can be used in many cases where the intrinsic vertical permeability might seem too low to allow success.

The SAGD process can be implemented at higher or lower pressures, provided there are no mobile water or gas zones present. If high pressure SAGD is used ( $p>>p_{o}$ but $\left\langle\sigma_{v}\right.$ ), the rate of processes aided by dilation and permeability enhancement will be further improved. However, heat transfer through vapour phase condensation (latent heat) is reduced at higher $\mathrm{p}$, and it will be necessary to depend more on sensible heat. Because the temperature is higher (e.g. $296^{\circ} \mathrm{C} @ 8 \mathrm{MPa}$ instead of $265^{\circ} \mathrm{C} @ 5 \mathrm{MPa}$ ), the oil viscosity will be lower, and this will also accelerate oil production rate.

In the absence of an understanding of geomechanics, reservoir engineers often argue that low-temperature SAGD is more efficient because of the higher enthalpy and the reduced rate of conductive heat losses in the wellbore and reservoir. But, a higher effective stress means dilation is partially suppressed, the permeability will be lower, and the viscosity of the oil will be lower as well (e.g. $215^{\circ} \mathrm{C} @ 2 \mathrm{MPa}$ ). When the coupled 
phenomena of thermal stress-related permeability enhancement and thermal viscosity reduction are factored in, it appears that low-T SAGD is disadvantageous, compared to high-T SAGD.

\subsection{Non-contact heating of a naturally fractured carbonate reservoir (NFCR)}

NFCR's are jointed rock masses with fracture-delineated blocks of porous limestone (or dolomite, marl, or mixed carbonates) containing oil in the pores. Because there are at least $2 \mathrm{~Tb}$ of heavy oil in such reservoirs worldwide, exploitation will take place eventually, likely based on some form of gravity drainage for flux and heating to lower viscosity. In 2007, a number of companies acquired large land positions in heavy oil NFCR's in Canada; it will be of interest to see if geomechanics lessons learned from exploitation of sandstones will be remembered and modified for the exploitation of the NFCR's.

NFCR's have pronounced property contrasts between intact matrix blocks and fractures. Furthermore, scale issues that arise with natural fracture networks make analysis complex and uncertainty-ridden. The overall reservoir may have a high 'macro-permeability', but intact blocks have a low 'micro-permeability'. In pressure-driven advective transport, high fracture permeability leads to advective instabilities (channelling). The rate of heating of the limestone blocks will be slow, perhaps even dominantly through conductive heat transfer because the permeability of the matrix block is generally in the range of $0.005-0.1 \mathrm{D}$. This value is also too low to allow for rapid drainage of oil from the matrix, where $99 \%$ of the oil is found.

Although no data exist publicly (and few data exist privately) for the case of high temperature SAGD or heating of a heavy oil NFCR, it is possible to speculate about the important geomechanics issues; they are to some degree similar to those arising in high-porosity sandstone reservoirs.

Figure 8 shows a blocky reservoir and a heated zone generated by induced high temperatures in a sealed horizontal well with offset production wells placed at the base of the zone. The sealed well is heated to $600^{\circ} \mathrm{C}$. Initially, heat transfer is dominated by conduction, but rapidly becomes convectively dominated. A large differential thermal expansion is induced within individual blocks because of temperature differences between the interior and the exterior. It is likely that this will lead to enhanced thermal microfissuring (tensile cracking) and fracturing of the limestone blocks, enhancing their internal permeability, which will then allow heat to enter the blocks more rapidly (convectively), and also allow hot oil to seep out.

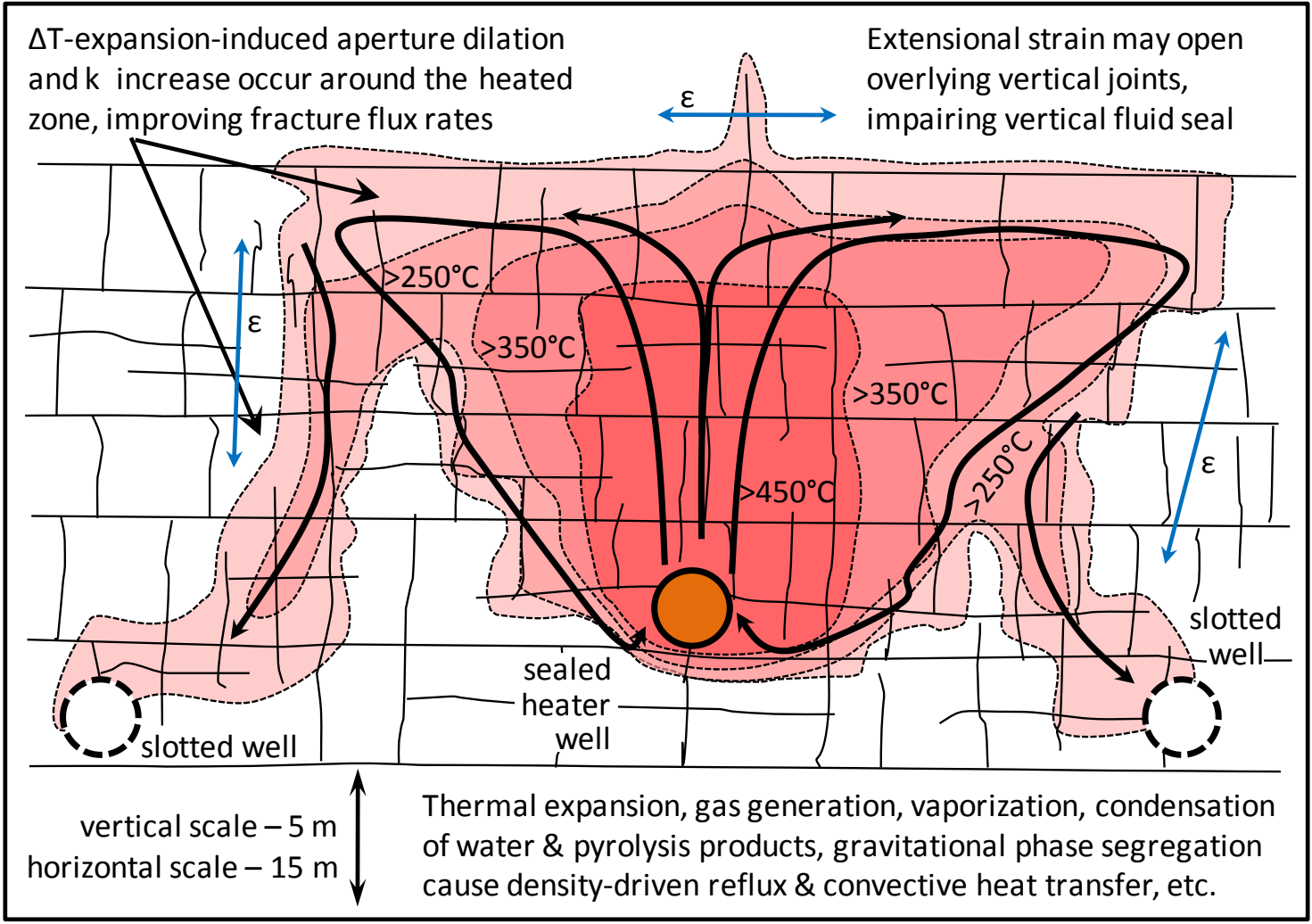

Figure 8 Heating a blocky limestone reservoir 
The general expansion of the heated zone leads to increases of radial stress outward from the heated zones, combined with reductions in tangential stress, in a manner similar to Figure 7. The tangential strains in advance of the thermal zone are extensional, so fracture apertures increase, and this has a sharp effect on permeability, allowing radially outward flux to be improved. Although the strength of the limestones is such that intact block shear failure and massive dilation are not expected to take place, the reservoir blocks are displaced by aperture opening and by small amounts of slip along the existing fractures. The elastic stiffness of intact limestone blocks is usually far greater than for high-porosity sandstones; values of E 20-30 GPa (and $v \sim 0.20$ ) are probably reasonable for a porosity of $\phi \sim 15-20 \%$. The thermal expansion coefficient is similar, about $10^{-5 \circ} \mathrm{C}^{-1}$. The high stiffness means that thermally-induced stress changes for a given $\Delta \mathrm{T}$ will be far higher than those in high-porosity sandstones, enough to cause slip along favourably oriented joints.

Hence, off the lateral flanks of the heated zone, the horizontal fractures will open as the blocks undergo small rotations; above the zone, the vertical fractures are opened because of the horizontal strain in the heated zone. These processes thus open joints, which greatly enhances the macro-permeability, but which also raises issues of seal maintenance if fluids escape above the heated zone. At the present time, even with coupled modelling, there are no results in the public domain that address such issues.

As temperature increases, gaseous phases are generated simply by the heat and strong thermal convection aided by density differences and condensation begins to take place. The gaseous phases initially are solution gas driven out of the oil by the high temperature, then steam, and eventually hydrocarbon gases from pyrolysis. Water and other liquids will condense in the cooler zones, flowing downward, largely under the effect of gravity segregation. As gases are generated, reducing effective stresses, opening of joints and shearing are facilitated at the low $\sigma^{\prime}$ conditions. Once temperature reaches $\sim 450-500^{\circ} \mathrm{C}$, pyrolytic reactions are intense, breaking apart large hydrocarbon molecules to generate lower viscosity (and hot) liquids, more gaseous products, and residual carbon.

At this stage, something similar to the heat transfer process in SAGD will become dominant. Steam and vaporised hydrocarbon gases rise gravitationally, condense, and flow back to the lower part of the reservoir as liquids where they can be produced. High temperatures, sufficient to pyrolize heavy oil, are moving into the intact reservoir blocks, generating huge differential thermal stresses that are large enough to promote fracturing. The drained pores are now gas filled (voidage replacement). Depending on the matrix permeability and the rate of heating, perhaps high pore pressures are generated inside the individual matrix blocks. Because gases are generated, their strong expansion potential can help propagate internal fracturing as it takes place. Of course, fracturing tends to suppress further elevated pore pressures within the blocks as permeable paths are generated.

To avoid large-scale pressure differences that could drive fluids too far from the process, the production wells are operated at back pressures commensurate with gravity-dominated flux. This means production of liquids low in the zone, with the condensing and non-condensing gases remaining high in the zone, perhaps withdrawn periodically.

In this case of thermal production from a heavy oil NFCR, a full thermal, hydromechanical and chemical process of great complexity is generated because of the strong heating and pyrolysis:

- A strong heat source generates an outwardly moving heated zone.

- Differential thermal heating of blocks leads to differential volumetric straining and high stresses, sufficient to fracture the rock and enhance the permeability.

- The geometry of the heated zone in the reservoir leads to dilation of joints through block rotation and some shear, massively enhancing the macro-permeability.

- High temperatures generate pyrolytic reactions in the heavy oil, generating lower-viscosity and gaseous phases with attendant large volume change effects.

- High pore pressures are generated because of heating, gas evolution, and gaseous products.

- Forced thermal convection takes place, with heat transfer through density-dominated flux, aided by condensation of steam and HC gases. 
- Forced density segregation of immiscible phases takes place as well, with fluids accumulating at the base of the zone, gases near the top.

- The heat transfer rates are massively affected and increased by the dilation of the joints and the internal fracturing of the limestone blocks, which are of course governed by stress effects.

Although this case as not yet been implemented in the field, there are massive first order effects of coupling that must be understood and as much as possible incorporated into models.

\subsection{Cyclic steam stimulation (CSS)}

CSS uses high pressure injection to achieve economically interesting thermal heating rates, followed by aggressive pressure depletion to help produce the heated, low-viscosity oil. Vertical or horizontal well arrays can be used, and there are many variations possible in terms of well management, stimulation volumes, injection rates, well configurations, and so on.

CSS is used mainly in high-viscosity heavy oils $(\mu>10,000 \mathrm{cP})$ where economically viable steam injection rates are possible only through hydraulic fracturing. In these viscous deposits, injection pressures on the first cycle quickly rise as continuous fracturing takes place and as $\sigma_{\mathrm{h}}$ increases to values above $\sigma_{\mathrm{v}}\left(\mathrm{p}_{\mathrm{inj}} \rightarrow 1.1-\right.$ $\left.1.2 \cdot \sigma_{\mathrm{v}}\right)$. This increase in $\sigma_{\mathrm{h}}$ may be attributed to four $\Delta \mathrm{V}$ processes:

- The creation of a fracture aperture in an elastic space generates a reaction stress.

- An increase in $\mathrm{p}$ reduces $\sigma^{\prime}$, thus generating a positive $\Delta \mathrm{V}$ in the region of $+\Delta \mathrm{p}$.

- Heat $(\Delta \mathrm{T})$ generates thermoelastic expansion of the sand matrix.

- The largest component of $\Delta \mathrm{V}$, thermal stresses and high pore pressures in a natural deviatoric stress field lead to massive general shearing and dilation, with attendant permeability increases.

After some time stress increases and stress rotations take place, leading to changes in fracturing direction (Dusseault and Simmons, 1982). Instead of a single fracture, a large volume 'fracturing zone' develops, with fractures changing attitude and orientation in response to the local stress changes. Nevertheless, the fracturing zone retains an elongation in the original direction of $\sigma_{\mathrm{HMAX}}$ because of the constraining effect of the far-field stress regimes on the process (Figure 9). This large number of fractures in different orientations leads to further improvements in permeability: the fractures cut through shale beds, perhaps as much as two to three metres thick, reducing the impact of lithological heterogeneity on flow. Steam is forced out to contact a large volume of reservoir rock.

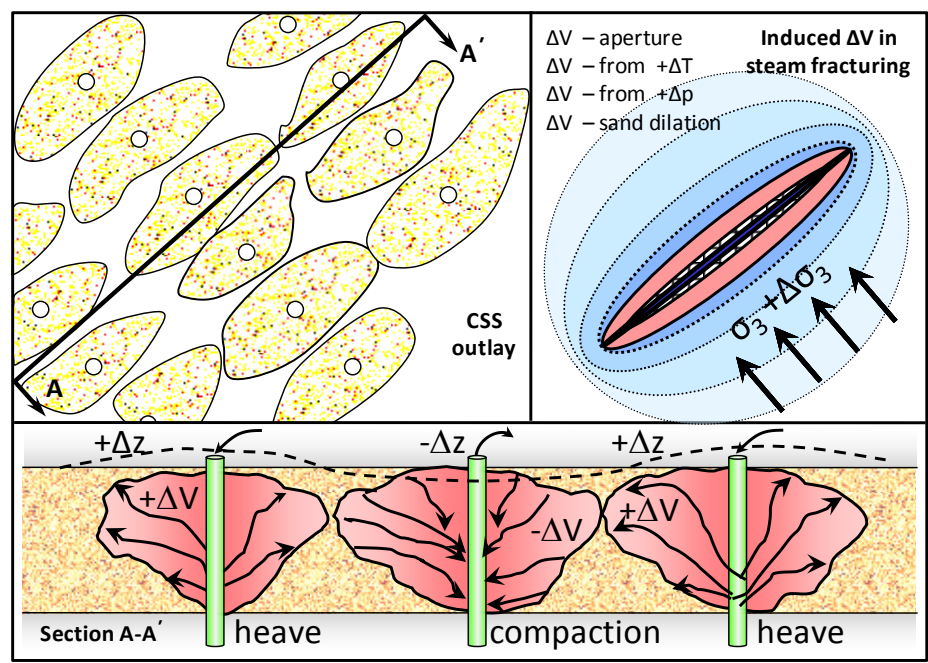

Figure 9 Cyclic steam stimulation (CSS) outlay, fracturing volume changes leading to stress changes, and on the bottom, a cross-section of a CSS process using injection and production in alternate rows 
As steam injection continues, $+\Delta \mathrm{V}$ accumulates because of continued dilation, in a manner similar to shear dilation during SAGD, but the $+\Delta \mathrm{V}$ potential is larger because the pore pressure is so high. Although no direct local measurements have been made, at high pore pressures, shear dilation from $\phi=0.30$ to $\phi \sim 0.38-0.42$ seems entirely feasible because of the low $\sigma_{3}^{\prime}$ condition during injection, and overall measured expansion of three to five per cent of the reservoir volume is testimony to the large amount of local dilation that is taking place because not all the reservoir is shearing. Very high pore pressures and massive reservoir expansion, combined with low heat flux rates into overlying shales (no forced convection), lead to strain incompatibility at the interfaces, causing massive well shear, a serious problem in all high pressure or cyclic steam injection operations.

During the injection phase, heat flux is dominantly through forced convective flow $(\Delta \mathrm{p})$. However, there are also components of gravity segregation as the steam phase and any evolved or co-injected gaseous phase seeks to rise because of low density, whereas condensed water and mobilised oil seek to sink because of high density. Because of low liquid mobility in the cold far-field, as long as there are no active (mobile) water zones, the injected and heated fluids tend to be restricted to a region around the well, dictated by the well pattern and the stress fields in situ, rather than by the intrinsic transport properties of the intact reservoir. In other words, because cold viscous oil in the pores is relatively immobile, fluid flux takes place mainly in the growing heated zone generated by fracturing, hence controlled by the intrinsic and induced stress fields.

During production, individual wells are subject to aggressive drawdown, and the following production mechanisms can take place:

- Because of large pressure gradients, there is pressure-driven flux to the production well. However, there are now new sources of expansion that can sustain pressure gradients:

- Gas (mainly $\mathrm{CH}_{4}$ ) driven from the oil during heating, released with $-\Delta \mathrm{p}$, and perhaps added in small amounts with the steam now expands.

- As p drops, free steam expands, but also, new steam is 'flashed' ( $\mathrm{p}-\mathrm{V}-\mathrm{T}$ and thermodynamic phase behaviour).

- Expanding gaseous phases rise because of gravity segregation, replacing liquids which are gravitationally displaced to the base of the zone, hence $\Delta \rho$-driven gravity segregation takes place, and this is particularly important if the production wells are horizontal.

- As $\mathrm{p}$ drops, $\sigma_{\mathrm{v}}^{\prime}$ increases and the highly dilated sand partially 'recompacts', driving liquids in the pores toward the producing wellbores, sustaining a driving $\Delta \mathrm{p}$.

- In some configurations, alternate well rows, perhaps $200 \mathrm{~m}$ apart, are placed on injection and production respectively, giving a component of steam line-drive to the production process.

Production continues for months, until oil rates become uneconomic. Thermodynamic cooling takes place, pressures are reduced, effective stresses rise, recompaction occurs, and some cold water influx may take place. Recompaction causes changes in permeability, although never going as low as original permeabilities, and compressibilities change massively as well because shear yielded sands are far more compressible than intact sands.

In the second and subsequent injection cycles, instead of observing $p_{\text {inj }}$ starting at $\sim 0.9 \cdot \sigma_{\mathrm{v}}$ and rising almost immediately to $1.1-1.2 \cdot \sigma_{\mathrm{v}}$, the initial injection is always found to be $\sim 0.3-0.4 \cdot \sigma_{\mathrm{v}}$, and, with each cycle, rises more-and-more slowly toward a fracturing value (Figure 10). This reflects the greatly increased injectivity in the heated depleted zone, the low pressure, and the partially gas-filled pore voids that must be recompressed as injection takes place.

Many subtle geometric effects take place during cyclic steaming, depending on the size of the zones with respect to the depth, and other factors. To date, there has been no published work relating the observed deformations to effective thermoporomechanical stress changes taking place in the reservoir.

The world's largest CSS project in Cold Lake, Alberta, producing $~ 160,000 \mathrm{~b} / \mathrm{d}$ bitumen $\left(25,000 \mathrm{~m}^{3} / \mathrm{d}\right)$, may be taken as the classic prototype. The reservoir is $\sim 460 \mathrm{~m}$ deep, $35 \mathrm{~m}$ thick, with porosity of $30 \%$. Intrinsic permeabilities are $0.5-1.5 \mathrm{D}$, viscosities $150,000 \mathrm{cP}$, pressures of $10-11 \mathrm{MPa}\left(\mathrm{T} \approx 315^{\circ} \mathrm{C}\right)$ are used to inject $\sim 200 \mathrm{~m}^{3} / \mathrm{d}$ of water equivalent (steam at $315^{\circ} \mathrm{C}$ ) through vertical wells drilled in a pattern reflecting 
the in situ stress fields. Adjacent vertical multi-well rows, oriented about $\mathrm{N} 40^{\circ} \mathrm{W}$ (in the $\sigma_{\text {hmin }}$ direction) are generally on production during this phase, a type of "alternating-row CSS". Vertical deformations above injection rows can reach $280-320 \mathrm{~mm}$ in a single cycle, with cumulative $\Delta \mathrm{z}$ reaching values of $600-800 \mathrm{~mm}$ (Figure 11).

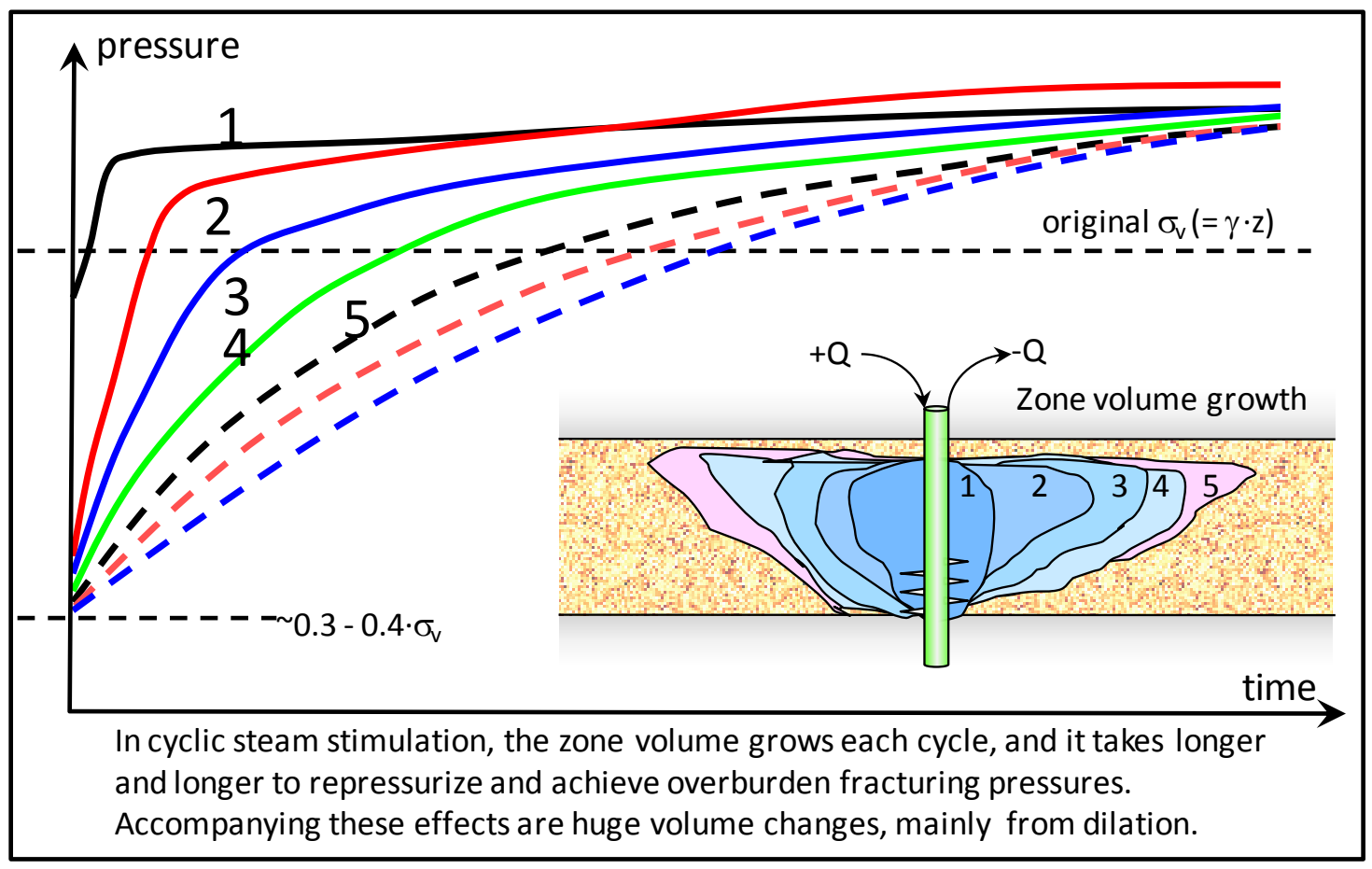

Figure 10 Massive stress and pressure changes accompany cyclic steam injection processes

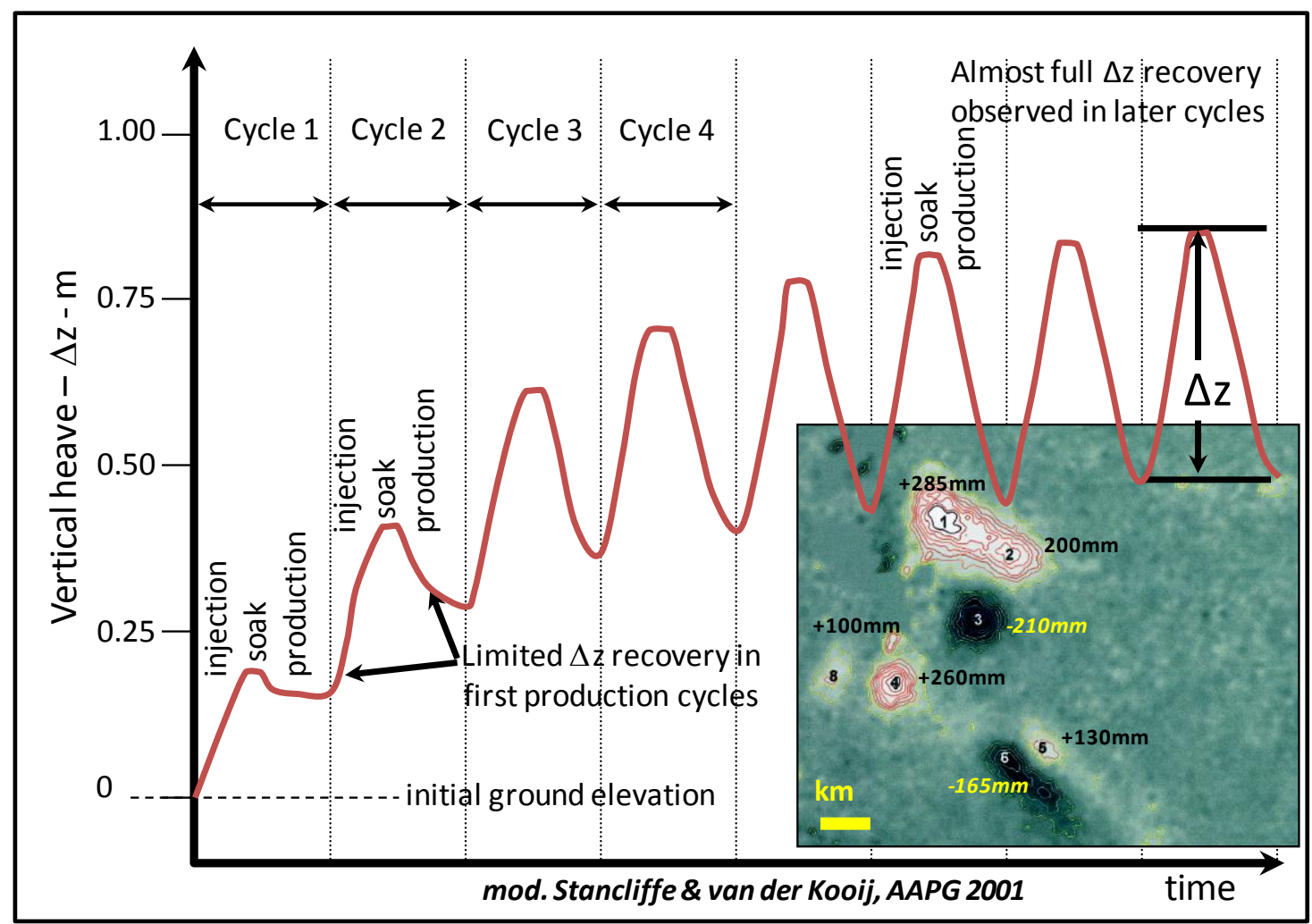

Figure 11 Vertical movements accompanying steam injection are largely because of shear dilation 
During a series of 12-20 injection/production cycles in CSS, various strategies may be followed, and moreand-more these strategies include consideration of coupled flow-geomechanics issues such as dilation, stress changes, recompaction drive, and so on. Gases $\left(\mathrm{CH}_{4}, \mathrm{~N}_{2}\right.$, etc.) or phases that condense as some cooling takes place in the reservoir may be added to enhance viscosity reduction and desirable phase behaviour. After five or six steam cycles, a pure solvent injection cycle may be used. After CSS is no longer economic, slow gas injection leads to additional production through a process known as gas-oil gravity drainage.

Finally, it is important to note that deformation monitoring of these processes, or for any coupled geomechanics process, is a necessary part of understanding the physics, the spatiotemporal progression of the process, and for calibrating and refining analysis methods (Dusseault, 2007; Dusseault and Rothenburg, 2002; Maxwell et al., 2007; Schmidt, 2005).

\section{Conclusion}

Coupling in geomechanics is a complex and fruitful area, helping to improve predictions and quantify various effects. There are many types of coupling, including dynamic coupling, chemical coupling, flow and temperature coupling, and so on.

The complexity and uncertainty that is associated with in situ thermal extraction processes was emphasised in this paper because of its great importance in energy resources provision, but also because it is an area where the degree of coupling among various processes is so large and consequential that it is a rich area in which to pursue developments. Iterative geomechanical coupling with petroleum industry flow simulators is perhaps the most viable way to introduce coupled geomechanics processes into systematic analysis.

\section{References}

Berryman, J. (1988) Seismic wave attenuation in fluid-saturated porous media, Pure and Applied Geophy, 128, pp. $423-432$.

Biot, M.A. (1941) General theory of three-dimensional consolidation, J. of Applied Physics, 12, pp. $155-164$.

Biot, M.A. (1956a) Theory of propagation of elastic waves in a fluid-saturated porous solid, Low frequency range; J. Acoust. Soc. Amer., 28, I, pp. 168-178.

Biot, M.A. (1956b) Theory of propagation of elastic waves in a fluid-saturated porous solid, High frequency range, J. Acoust. Soc. Amer., 28, pp. 179-191.

Charlez, P.A. (1997) Rock Mechanics Vol. 2, Petroleum Applications, Editions Technip, Paris.

Chin, L.Y. and Nagel, N.B. (2004) Modeling of subsidence and reservoir compaction under waterflood operation, Int. J. Geomech., 4, pp. 28-34.

Chin, L.Y., Raghavan, R. and Thomas, L.K. (2000) Fully Coupled Geomechanics and Fluid-Flow Analysis of Wells with Stress-Dependent Permeability. SPE Journal 5(1), pp. 32-45.

Cocco, M. and Rice, J.R. (2002) Pore pressure and poroelasticity effects in Coulomb stress analysis of earthquake interactions, J. Geophysical Research, 107, B2, 10, 1029 p.

Collins, P.M. (2007) Geomechanical Effects on the SAGD Process, SPE Reservoir Evaluation and Engineering, V10N4, August, SPE 97905-PA.

Collins, P.M., Carlson, M.R., Walters, D.A. and Settari, A. (2002) Geomechanical and Thermal Reservoir Simulation Demonstrates SAGD Enhancement Due to Shear Dilation, Proc SPE/ISRM Rock Mechanics Conf., Irving TX,

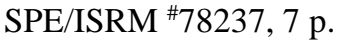

Cryer, C.W. (1963) A comparison of the three-dimensional consolidation theories of Biot and Terzaghi, Quart. J. of Mechanics and Applied Mathematics, 16(4), pp. 401-412.

de la Cruz, V. and Spanos, T.J.T. (1985) Seismic Wave Propagation in a Porous Medium, Geophysics, 50(10), pp. $1556-1565$.

de la Cruz, V. and Spanos T.J.T. (1989) Thermomechanical Coupling during Seismic Wave Propagation in a Porous Medium, J. Geophysical Research, 94, pp. 637-642.

de la Cruz, V., Sahay, P.N. and Spanos, T.J.T. (1993) Thermodynamics of porous media, Proc. of the Royal Society of London A, 433, pp. 247-255.

Dean, R.H., Gai, X., Stone, C.M. and Minkoff, S.E. (2006) A comparison of techniques for coupling porous flow and Geomechanics, SPE Journal 2006, 11(1), pp. 132-140.

Detournay, E. and Cheng, A.H-D. (1988) Poroelastic response of a borehole in a non-hydrostatic stress field, Int. J. for Rock Mechanics and Mining Sciences and Geomechanics, Abstracts 25(3), pp. 171-182.

Di Maio, C., Hueckel, T. and Loret, B. (2002) Proceedings Workshop on Chemo-Mechanical Coupling in Clays, Balkema, Rotterdam. 
Dusseault, M.B. (2007) Monitoring and modeling in coupled geomechanics processes, Proc. CIPC, Calgary, Paper 2007-028, 10 p.

Dusseault, M.B. and Rothenburg, L. (2002) Deformation analysis for reservoir management, In Oil and Gas Science and Technology - Revue de l'IFP, Vol. 57, No. 5, pp. 539-554.

Dusseault, M.B. and Simmons, J.V. (1982) Injection-induced stress and fracture orientation changes, Canadian Geotechnical J., 19(4), pp. 483-493.

Dusseault, M.B., Bruno, M.S. and Barrera, J. (2001) Casing Shear: Causes, Cases, Cures, SPE Drilling and Completion, 6(2), pp. 98-107.

Dusseault, M.B., Yin, S., Rothenburg, L. and Han, H.X. (2007) Seismic monitoring and geomechanics simulation, Leading Edge, June 2007, pp. 610-620.

Fung, L.S.K., Buchanan, L. and Wan, R.G. (1994) Coupled geomechanical-thermal simulation for deforming heavy oil reservoirs, J. Canadian Petroleum Technology 33(4), pp. 22-28.

Gai, X., Dean, R.H., Wheeler, M.F. and Liu, R. (2003) Coupled geomechanical and reservoir modeling on parallel

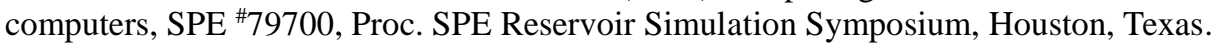

Gatmiri, B. and Delage, P. (1997) A formulation of fully-coupled thermal-hydraulic-mechanical behaviour of saturated porous media - numerical approach, Int. J. for Numerical and Analytical Methods in Geomechanics, 21, pp. 199-225.

Geilikman, M.B., Spanos, T.J.T. and Nyland, E. (1993) Porosity diffusion in fluid-saturated media, Tectonophysics 217, pp. 11-115.

Geertsma, J. (1973) A Basic Theory of Subsidence due to Reservoir Compaction: The Homogeneous Case, Verh. Kon. Ned. Geol. Mijnbouwkundig Genootschap, 28, pp. 43-62.

Ghaboussi, J. and Wilson, E.L. (1973) Flow of compressible fluid in porous elastic media, International Journal of Numerical Methods in Engineering, 5, pp. 419-442.

Horne, R.N. (1995) Modern Well Test Analysis: A Computer-Aided Approach, Petroway, Inc., Palo Alto, CA.

Huyghe, J.M., Raats, P.A.C. and Cowin, C. (editors) (2005) Section 3 on Poromechanics, Geomechanics and Porous Media in IUTAM Symposium on Physicochemical and Electromechanical Interactions in Porous Media. Solid Mechanics and its Applications Series XXVIII, Berlin, Springer Verlag, 373 p.

Kranz, R.L., Saltzman, J.S. and Blacic, J.D. (1990) Hydraulic diffusivity measurements on laboratory rock samples using oscillating pore pressure method, Int. J. Rock Mech. Min. Sci. and Geomech. Abstr., 27(5), pp. 345-352.

Lomba, R.F.T., Chenevert, M.E. and Sarma, M.M. (2000) The role of osmotic effects in fluid flow through shales, J. Petroleum Science and Engineering, 25(1-2), pp. 25-35.

Malekzadeh, F.A. and Pak, A. (2008) A discretized analytical solution for fully-coupled simulation of heat and mass transfer in poroelastic unsaturated media, accepted for publication by the Int. J. Numerical and Analytical Methods in Geomechanics, in press.

Manga, M., Brodsky, E.E. and Boone, M. (2003) Response of streamflow to multiple earthquakes, Geophysical Research Letters, 30(5), 1214 p.

Mavko, G., Mukerji, T. and Dvorkin, J. (1998) The rock physics handbook, Cambridge University Press, Cambridge.

Maxwell, S.C., Du, J., Shemeta, J.E., Zimmer, U. and Boroumand, N. (2007) Monitoring SAGD Steam Injection Using Microseismicity and Tiltmeters, paper SPE 110634-MS, Proc. 2007 SPE ATCE, Anaheim, CA, 11-14 November, $7 \mathrm{p}$.

Mesri, G.R. and Rokhsar, A. (1974) Theory of Consolidation for Clays, Journal of the Geotechnical Engineering Division, 100(8), pp. 889-904.

Minkoff, S., Stone, C., Bryant, S., Peszynska, M. and Wheeler, M. (2003) Coupled Fluid Flow and Geomechanical Deformation Modeling, J. Petroleum Science and Engineering, 38(1-2), pp. 37-56.

Mitchell, J.K. (1991) Conduction phenomena: from theory to geotechnical practice, Géotechnique, 41, pp. $299-340$.

Montgomery, D.R. and Manga, M. (2003) Streamflow and Water Well Responses to Earthquakes, Science 300 , pp. 2047-2049.

Muskat, M. (1937) The flow of homogeneous fluids through porous media, McGran-Hill, New York, 763 p.

Nadeem, M. and Dusseault, M.B. (2007) Geological engineering criteria for deep waste disposal. Environmental Geosciences, 14(2), pp. 61-77.

Nur, A. (1971) Viscous phase in rocks and the low-velocity zone, J. Geophysical Research, 76, pp. 1270-1277.

Osorio, J.G., Chen, H.Y. and Teufel, L.W. (1999) Numerical simulation of the Impact of Flow-Induced Geomechanics Response on the Productivity of Stress-Sensitive Reservoirs, SPE Reservoir Simulation Symposium, Houston, Paper SPE \#51929.

Ottemöller, L., Nielsen, H.H., Atakan, K. and Havskov, J. (2005) The 7 May 2001 induced seismic event in the Ekofisk oil field, North Sea, J. Geophysical Research 110, B10301, 15 p.

Paul, S. (1976) On the Disturbance Produced in a Semi-Infinite Poroelastic Medium by a Surface Load, Pure and Applied Geophysics, 114(4), pp. 615-627.

Rothenburg, L. and Bathurst, R.J. (1989) Analytical Study of Induced Anisotropy in Idealized Granular Materials, Géotechnique 39(4), pp. 601-614. 
Rothenburg, L., Bratli, R.K. and Dusseault, M.B. (1994) A poroelastic solution for transient fluid flow into a well, PMRI Publications, University of Waterloo, Canada, (available upon request from mauriced@uwaterloo.ca).

Samier, P., Onaisi, A. and Fontaine, G. (2006) Comparisons of uncoupled and various coupling techniques for practical field examples, SPE Journal, 11(1), pp. 89-102.

Santamarina, C., Fam, M., Fratta, D. and Cascante, G. (1998) Solid-Fluid Coupling Phenomena in Particulate Media, Proc. Biot Conference in Poromechanics, Thimus, J-F., Abousleiman, Y., Cheng, A.D.H., Coussy, O., Detournay, E. (editors), Louvain-la-Neuve, Belgium, Balkema, Rotterdam, pp. 615-620.

Schmidt, D.R. (2005) Rock Physics and Time-Lapse Monitoring of Heavy-Oil Reservoirs, paper PS2005-435, SPE/PSCIM/CHOA 98075, Proc. joint CHOA/CIPC/SPE ITOHOS, 1-3 November, Calgary, Alberta, 6 p.

Settari, A. and Mourits, F.M. (1998) A coupled reservoir and geomechanical simulation system, SPE Journal. September, pp. 219-226.

Settari, A. (2002) Reservoir compaction. J. Petroleum Technology 5(8), pp. 62-69.

Showalter, R.E. (2002) Diffusion in deformable media, Resource Recovery, Confinement, and Remediation of Environmental Hazards, J.M. Chadam, A. Cunningham, R.E. Ewing, P.J. Ortoleva and M.F. Wheeler (editors), The IMA Volumes in Mathematics and its Applications, Springer, pp. 115-130.

Smith, D. and Booker, J. (1993) Green's function for fully coupled thermoporoelastic material, Int. J. Numerical and Analytical Methods in Geomechanics, 17, pp. 139-163.

Spanos, T.J.T., Shand, D., Davidson, B.C., Dusseault, M.B. and Samaroo, M. (2003) Pressure pulsing at the reservoir scale: a new IOR approach, J. Canadian Petroleum Technology, 42(2), pp. 16-28.

Spanos, T., Udey, N. and Dusseault, M.B. (2002) Completing Biot Theory, Proc. 2nd Biot Conf. on Poromechanics, Grenoble France, August, Balkema, Rotterdam, pp. 819-826.

Stone, T., Bowen, G., Papastasiou, P. and Fuller, J. (2000) Fully-coupled Geomechanics in a Commercial Reservoir Simulator, Proc. SPE European Petroleum Conf., Paris, Paper SPE \#65107.

Terzaghi, K. (1943) Theoretical Soil Mechanics. Wiley, New York.

Thomas, L.K., Chin, L.Y., Pierson, R.E. and Sylte, J.E. (2002) Coupled Geomechanics and Reservoir Simulation, SPE \#7723, Proc. Annual Technical Conference and Exhibition, San Antonio, Texas.

Tortike, W.S. and Farouq Ali, S.M. (1987) A framework for multiphase nonisothermal fluid flow in a deforming heavy oil reservoir, Proc SPE Symposium on Reservoir Simulation, San Antonio TX, Paper SPE \#16030.

Tran, D. and Nghiem, L. (2005) An Overview of Iterative Coupling between Geomechanical Deformation and Reservoir Flow, SPE Int. Thermal Operations and Heavy Oil Symposium, Calgary, Alberta, SPE/PSCIM/CHOA \#97879, Paper PS-2005-396.

Verruijt, A. (1969) Elastic Storage in Aquifers, Chapter in Flow Through Porous Media, (editor) R.J.M. De Wiest, Academic Press, New York City, pp. 331-376.

Wang, Y. and Dusseault, M.B. (2003) A coupled conductive-convective thermo poroelastic solution and implications for wellbore stability, J. Petroleum Science and Engineering 38, pp. 187-198.

Yin, S., Rothenburg, R. and Dusseault, M.B. (2008a) Analyzing Production-Induced Subsidence using Coupled Displacement Discontinuity and Finite Element Methods, Computer Methods in Engineering Sci., 469(1), pp. $1-10$.

Yin, S., Dusseault, M.B. and Rothenburg, L. (2008b) Thermal Reservoir Modeling in Petroleum Geomechanics, Int. Journal of Analytical and Numerical Methods in Geomechanics, in press.

Zimmerman, R.W. (2000) Coupling in poroeasticity and thermoelasticity, Int. J. of Rock Mechanics and Mining Sciences, 37(1), pp. 79-87. 